\title{
Study on Dynamic Mechanism of Chinese Rural Social Security from the Perspec- tive of Ecology
}

\author{
Haobang $\mathrm{Wu}^{1}$ Li Wang ${ }^{2}$ Yin Feng ${ }^{3}$ \\ ${ }^{12}$ School of Political Science and Public Administration, University of Electronic Science \\ and Technology of China, Chengdu, 611731 \\ ${ }^{3}$ School of Computer Science and Technology, Southwest University for Nationalities of \\ China, Chengdu, P.R. China, 610041
}

\begin{abstract}
Rural social security system is a living and unnatural system, and both its global and local development will maintain close ties and mutual interactions with the surrounding environment. This paper explores a dynamic mechanism on the basis of ecological theory to promote the continuous development of the social security system in rural areas. Then, from the point of view of the government, it puts forward some countermeasures and suggestions for the effective operation of the dynamic mechanism of rural social security so as to promote the healthy functioning of the rural social security.
\end{abstract}

Keywords: Ecological theory, Rural social security, Dynamic mechanism, Countermeasures and suggestions

\section{Introduction}

Rural social security is provided by the State as a public good, and is an important guarantee for the basic livelihood of rural residents. In the vast rural areas, people whose social security needs can not be met account for the most part of the whole population of rural residents, which has a serious impact on the social stability in rural areas. It requires strong and stable power boost for establishing and improving the rural social security. However, the ecosystem is a system which can continue to generate power to achieve an infinite loop, proliferation with the close contact with the environment and its own internal interaction. In recent years, it is increasingly recognized in the theoretical circles and academic circles that the ecological theory is employed to study the economic and management issues. The eco-rural social security is able to inject new impetus into the rural social security which is conducive to promoting the sustainable development of rural social security, meanwhile it enables the rural social security to truly become "stabilizer" and "propeller" for the rural society.

\section{Theoretical Foundation of the "Ecology" of Rural Social Securi- ty}

\subsection{Ecological theories}

Currently, the ecological theory is well developed and has been widely used in information, economy and management,etc. It provides a new research perspective for the social sciences. This article will employ the following several ecological theories to study the dynamic mechanism of rural social security. 


\subsubsection{Ecological systems theory}

Ecosystem is a system for interactions between the species and its surrounding environments. It is composed by the biological communities and their environments as a whole in a certain range of time and space ${ }^{[1]}$. This unity has a certain size and structure, each member in it can make use of the energy flow, nutrient circulation and information transmission to be interrelated, interacted and interdependent, and form a complex unity with self-organizing and self-regulating function.

\subsubsection{Niche theory}

Niche refers to the time, location and function of spatial relationships of each species in the community, at a particular system at a particular time; or it is the relative position of one organism to other species within this community. The niche not only has a certain space and area, and the species on the niche also shows dependencies with the surrounding environment or other species ${ }^{[2]}$.

\subsubsection{Ecological factor theory}

Ecological factor refers to the factors in the ecosystem environment that have a direct or indirect impact on the biological growth, development, reproduction, and many other physiological functions ${ }^{[3]}$. Ecological factors are essential environmental conditions for the survival of biological lives and they give support for the organisms'lives, maintaining the survival of the system, and promoting the system's continuous circulation. It specifically includes light, temperature, water, plants, animals,etc.

\subsubsection{The dynamic mechanism of eco- system}

Ecosystem development is a process with continuous improvement and circulation. The material, energy and information keep flowing between the species and the environment in the ecosystem, and the inputs and outputs between species and environments are coexisting simultaneously. Species generate new substances for compensating the environment while utilizing the resources, thereby promoting the recycling of resources. It is worth noting that the external environment's being a catalyst for the ecosystem is the key to circulating power of ecosystems. External environment stimulates the factors to join in, which will have a strong influence on ecological species, and can greatly facilitate the effective functioning of the ecosystem.

\subsection{The ecosystem of rural social se- curity}

Chinese rural social security is a system constituted by the new rural endowment insurance, new rural cooperative medical insurance system, rural social welfare and other security projects. Like the ecosystem, the rural social security system also has a certain structure. Under the overall institutional framework, it will achieve its continuous development through the stimulus of the external funding, material, policy and other incentives. Meanwhile, it can also generate some economic and social benefits to repay the external environment. It constitutes a whole unity with interaction, interdependence and common development between the external environment, and this community can be called as the rural social security ecosystem. The ecological characteristics of the rural social security system manifest in the following:

- Stability. Protection projects of rural social security will eventually come to a stable state after constant reform and innovation, including the stability of the amounts and contents of the protection projects, etc.

- Serviceability. The ecosystem provides humanity with a variety of 
environmental conditions for production during its activities, and similarly, the rural social security system provides the basic living guarantee for rural residents.

- Evolution. Rural social security system is experiencing from junior development process to senior one like the ecosystem. Rural social security system realizes the optimization of the structure and content while in constant development and advancement.

- Sustainability. Ecosystem is a circulatory system developed in the thousands of millions of years, and the rural social security system also achieves energy exchange, liquidity through the uptake of "nutrient" and feedback of "Oxygen", and prompts sustainable development of the system.

\section{Dynamic Mechanism of Rural So- cial Security Ecosystem}

\subsection{An analysis of dynamic mecha- nism of rural social security eco- system}

Rural social security ecosystem is developing continuously. It exists in certain political, economic and social environment, and its level of development is affected by the interaction of environmental factors. Various security projects within the system will be showing a a process of gradual improvement in the content, structure and other aspects in the strong stimulation and catalyst of external factors. Therefore, an in-depth study of dynamic mechanism of rural social security ecosystem has an extremely important significance for speeding up the development of Chinese rural social security system. In the functioning of rural social security ecosystem, its dynamic mecha- nism can be explored from the following aspects:

- Excitation of dynamic source

- Exploration of striving forces

- Maintenance of the striving forces

- Distribution of the striving forces

3.2. Building the dynamic mechanism of rural social security ecosystem

How to put the ecological theory of dynamic mechanism into practice, need to build a comprehensive dynamic mechanism for social security ecosystem according to the actual situation in rural areas. Constructing the dynamic mechanism of the rural social security ecosystem should take the following into consideration: the government policies; rural residents, guidance of interests, monitoring and evaluating and other factors. The dynamic mechanism of rural social security ecosystem can be subdivided into the following five mechanisms to elaborate how to construct it.

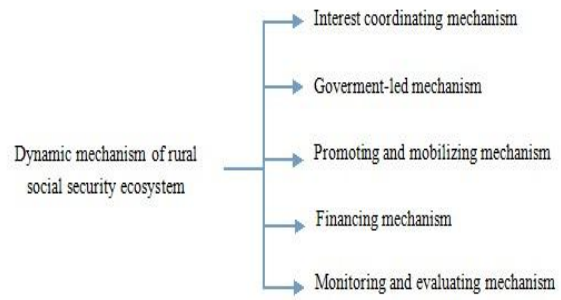

Fig. 1: The dynamic mechanism of rural social security ecosystem.

\subsubsection{Interest coordinating mechanism}

There must be relevant stakeholders in a variety of economic activities. It is selfevident that the coordination of the stakeholders in the rural social security has a particular significance to the building of the rural social security ecosystem.

Firstly, the socialist market economy is a kind of economy that the market plays a fundamental role in the allocation of resources under the macro-control of the 
nation. How to coordinate the interests of the government and the market is the most important issue. The government should provide construction funds for the platform through government funds and government financial transfer payments, and provide the platform with access conditions and sustainable development conditions through agriculture policy and market policy. The market can make use of the stakeholders platform to furnish the rural social security ecosystem with benign financial and technical support, and it can also integrate the rural social security ecosystem with the market to optimize the allocation of resources and achieve the maximization of resource utilization $^{[4]}$.

Secondly, it is necessary to coordinate the interests and responsibilities between the Government and the collective and the individual. Due to Chinese current level of economic development as well as the reality of a huge population base, it is consistent with the current situation in China to assign the rural social security burden to the state, the collective and the individual farmers. Therefore, there is no doubt that the rights and obligations among these three stakeholders should be explicitly regulated, and the boundaries of their respective responsibilities should be drawn ${ }^{[5]}$. It must still rely on the government to achieve a virtuous cycle built on these three stakeholders. In addition to funding, the state can promote farmers' income levels through industrial policies, which will also reduce the burden on the state and the collective, thus achieving a better balance of interests.

\subsubsection{Government-led mechanism}

The construction of the dynamic mechanism of rural social security ecosystem still needs to establish a government-led mechanism to give it a full support.

In the construction of social security in rural areas, the government should be charged with building the institutional framework and promoting strategy for rural social security in line with the economic development level, establishing and improving the management of rural social security system. It should honor the state's fiscal responsibility for rural social security to ensure the appreciation of the rural social security funds. Besides, it should also push forward the establishment of a sound regulatory mechanism of rural social security to promote the construction of rural social security legislation, as well as creating a suitable social environment for the construction of rural social security ecosystem,etc. Specifically, the government should fully implement their duties, and make best use of government capacity to formulate an overall strategy for rural social security ecosystem. What's more, the state can fundamentally promote the development of rural areas; break the urban-rural dual structure through optimization of allocating resources.

\subsubsection{Promoting and mobilizing mechanism}

Although China has established the new rural endowment insurance system and the new rural cooperative medical insurance system currently, the insurance rate have been very low. Faced with this situation, it is in urgent need to timely establish the promoting and mobilizing mechanism.

First of all, the local government needs to pay attention to carrying out various forms of promoting activities, and conducting an in-depth publicizing for the rural social security ecosystem. It is essential to write pamphlets, to release the film into the peasant families and to elaborate the promoting activities to the farmers by grassroots cadres so that farmers can recognize the necessity of rural social security ecosystem. While strengthening the government's accountability, the establishment of evaluation system needs to be formed for supervising civil servant's 
work. Meanwhile, the farmers will preach to express their own feelings about the added benefits of the social security ecosystem in rural areas. Such kind of publicity can effectively guide the farmers to join in it.

\subsubsection{Financing mechanism}

A personal account can be created for recording of individual contributions from rural residents so as to realize reserve accumulation. Both the individual contributions and collective subsidies for farmers will be recorded in the name of individual farmers, as a result, the farmers can see the real capital accumulation, which will effectively motivate farmers to actively participate. The profits of the township enterprises are one of the sources for collective subsidies. Therefore, developing industries in rural areas is one of the measures to effectively alleviate the shortage of rural social security funds; while the government finances are the largest sources for rural social security funds, on this basis, the scale of the fiscal expenditure needs to be expanded to support the rural social security funds. At the same time, the best choice is to introduce the social security tax, it can provide stable and reliable funds for rural social security ${ }^{[6]}$.

In addition, it is inevitable to open up new sources of funding for rural social security financing. Businesses, civil society organizations, social welfare organizations and other organizations are all potential sources of funds, the government can take advantage of tax leverage, preferential policies and other incentives to encourage them to invest in rural social security. Meanwhile, the government can lead the social welfare lottery into the social security in rural areas, and guide the welfare lottery to tilt to the rural social security.

\subsubsection{Monitoring and evaluating mechanism}

For the construction of supervision mechanism, firstly, the law must act as a yardstick to restrain the codes of conduct of the various subjects in the rural social security system. In this regard, the relevant laws of the rural social security system should be developed and improved. Secondly, the government should establish a specialized and independent supervision mechanism for normal operation of rural social security system. The supervision agency may be led by the government, and at the same time invite the experts, social media, and the public to supervise jointly. Finally, with regard to the funding operation of rural social security system, the third-party authoritative accounting agencies can be invited to involve in the accounting of the funds, so independent accounting of funds is achieved to effectively prevent corruption and waste, and misappropriation of occupation.

As for the construction of the evaluation mechanism, an evaluation system in line with the rural social security system can be developed based on the evaluation of the effectiveness of economic behavior. For example, the data related to the rural social security can go through an in-depth evaluation so that it can be assessed that each content and link in the rural social security system. At the same time,the Principle of Marginal Economics of Scale can be adopted to assess the effectiveness of the social security system in rural areas, which requires the government to analyze and interpret from an perspective of economics. 


\section{Countermeasures and Suggestions for Effective Operation of the Dy- namic Mechanism of Rural Social Security Ecosystem}

\subsection{Increasing the government's em- phasis on rural social security}

Social security is a social security system dominated by the government. Therefore, whether the Government values it or not is not only related to effective operation of dynamic mechanism of the rural social security ecosystem, but is related to the rise and fall throughout the rural social security. The government who wants to attach great importance to the rural social security needs to do the following two points: firstly, the long-term and overall strategic planning concerning the development of rural social security requires to be developed and be integrated into the national development plans in the future. According to the time period for the division, it can be made as the short, medium and long term strategic planning lasting respectively for five, ten, or fifteen years;secondly, things need to be done to closely monitor the influence social changes have on rural social security ecosystem, constantly adjust, reform, and innovate the rural social security system, and promote the great development of rural social security.

\subsection{Promoting the legislation process of rural social security}

Using the legal weapons to protect the interests of rural residents are the prerequisite for the functioning of the rural social security ecosystem. Dynamic mechanism of rural social security ecosystem requires the government to strengthen legislation to protect its smooth operation Firstly, the government should pass laws to standardize the central and local policies and regulations to the legal aspects, and should also clearly specify rules and requirements of the implementation; sec- ondly, the law should also stipulate the various projects that needs to be organized and implemented in rural social security in China recently, including the specific content of the protection projects, the effects of implementation, as well as responsibility sharing of the government, the collective and the individual in the operation of the project; thirdly, the relevant legislation should also make clear the role the central and local government play, and in particular, determine the financial investment ratio of the government and the states; finally, the government should accelerate the improvement of "Social Insurance law", and make it tilt to the rural social security.

\subsection{Bettering the management system of rural social security}

The government should do their utmost to manage the social security system. Firstly, adhering to the principle of public affairs separated from the political affairs, the rural social security administration needs to be separated from the fund management, and business management. The government is mainly responsible for the daily administration work of rural social security, while operations of the fund should be managed by professional fund management companies; secondly, insisting on the principle of clear responsibilities, efficient collaboration. Administration rights and responsibilities of the relevant departments of rural social security should be institutionally defined, so as to make it work in a coordinated and efficient manner ${ }^{[7]}$; thirdly, strengthening the supervising mechanism of rural social security. People's Congress, especially people's congress in each state can be used to achieve supervision. Meanwhile, the media, civil society organizations and supervision of the public can also play an important role. 


\subsection{Strengthening the construction of rural social security personnel}

Establishing a high-quality, professional rural social security personnel is a practical requirement for the dynamic mechanism of rural social security ecosystem. Firstly, it is quite important to create a good environment, and improve the talent incentive mechanism in order to attract and encourage college graduates and social talents to join in the rural social security work; secondly, regular business training courses have to be carried out so that the rural social security staffs can learn the advanced management knowledge and experience of social security, and continuously improve their ability to work efficiently; Finally, work experience exchanging activities should be held in the social security departments in all towns and cities to better improve the service levels of staffs working for rural social security in order that the staffs can learn from each other, and mutually benefit, and promoting the rural social security work smoothly.

\section{Conclusion}

Rural social security issues relate tightly to the harmony and stability in Chinese rural areas. Based on the ecological perspectives, five sustainable mechanisms are constructed in accordance with the reality of rural social security. However, owing to the "duality" feature in the urban and rural areas in the Chinese social security system, it is not enough to study the rural social security ecosystem just from the perspective of dynamic mechanism; it is also in urgent need to improve the nutritional supply mechanism, metabolic mechanisms for the entire ecosystem of social security in rural areas. With the central government increasing attention and care for rural utilities gradually, it is obvious that the Chinese rural social security will have a better development in the future.

\section{References}

[1] Yaning Chu and Bing Luo, "Study on the Construction of Ecological Power System Based on the 'Institution- Information-Collaboration' Technology Innovation"'J]. Shandong Textile Economy, 2010 (1).

[2] Donghong Wang, "Research on Enterprise Evolutionary Force Based on Niche Perspective"[J], Enterprise Economy, 2012 (9).

[3] Yue Jia, "Research on Construction and Operation Mechanism of Regional Innovation System Based on Ecology Theory"[D], Harbin University of Science and Technology, Master's Degree Thesis, 2010.

[4] Desheng Zhou, "The Study on the Governmental Responsibility of Developing Village Endowment Insurance"[D], Jilin University, Master's Degree Thesis, 2007.

[5] Ruimin Liang, Study on the Status and Dynamic Mmechanism of Shanghai Elderly Welfare Socialization"[D], Shanghai University of Engineering Science, Master's Degree Thesis, 2010.

[6] Hongwu Liu, "Innovative Study on the Rural Social Security System in China"[D], East China Normal University, Master's Degree Thesis, 2005.

[7] Xueping Meng, "Study on the Government Responsibility in the Construction of Rural Social Security System"[D], Chongqing Normal University, Master's Degree Thesis, 2007. 